\title{
Paper
}

\section{Thermal Conductivity of Al/SiC Particulate Composites Produced by Friction Powder Sintering}

\author{
Yoshihisa KIMOTO $^{1}$, Toru NAGAOKA ${ }^{1}$, Kiyoshi MIZUUCHI ${ }^{1}$, \\ Masao FUKUSUMI ${ }^{1}$, Yoshiaki MORISADA² and Hidetoshi FUJII ${ }^{2}$ \\ 'Osaka Municipal Technical Research Insititute, 1-6-50 Morinomiya, Joto-ku, Osaka 536-8553, Japan. \\ ${ }^{2}$ Joining and Welding Research Institute, Osaka University, 11-1 Mihogaoka, Ibaraki 567-0047, Japan.
}

Received December 8, 2015; Revised January 4, 2016; Accepted January 7, 2016

\begin{abstract}
Friction powder sintering (FPS) is a recently-developed technique to produce particulate metal matrix composites (PMMCs). In FPS, powders including metallic and ceramic particles are compacted by the pressure and frictional heat induced by a rotating tool. We have applied FPS to obtain Al-50 vol.\% SiC PMMCs and evaluated the thermal conductivity of the composites. FPS has been performed under the tool rotating rate of $1500 \mathrm{rpm}$ and tool pressure of $31 \mathrm{MPa}$. By extending the sintering time from 1 minute to 2 minute, the relative packing density has increased from $81 \%$ to $91 \%$, and the thermal conductivity has been enhanced from $66 \mathrm{~W} / \mathrm{mK}$ to $110 \mathrm{~W} / \mathrm{mK}$. It has been noted that the further densification of the composites is necessary to draw the potential thermal conductivity.
\end{abstract}

KEY WORDS

friction powder sintering, aluminum, $\mathrm{SiC}$, composite, thermal conductivity

\section{Introduction}

Friction stir welding $(\mathrm{FSW})^{1,2)}$ is a relatively new solid state joining process shown in Fig. 1 (a). In the FSW, a rotating tool is inserted onto the side surfaces of two plates, and traversed along the welding direction to form the joint. The microstructure of the stir zone is refined through the dynamic recrystallization due to the severe strain, frictional heat and rapid cooling ${ }^{2}$. Since the invention of FSW, a wide variety of friction stir technologies have been presented. Friction stir processing (FSP) ${ }^{2,3)}$ shown in Fig. 1 (b) is an application of the FSW to the surface modification for a single plate. FSP can also refine the microstructure in the stir zone through the dynamic recrystallization and densify the cast and sintered materials by eliminating pores ${ }^{4,5)}$. Friction stir powder processing (FSPP) is an application of FSP to the fabrication of a surface composite ${ }^{6}$. In a typical FSPP, ceramic powder particles are filled into the groove machined on the plate, and FSP is performed over the groove ${ }^{7)}$ as shown in Fig. 1 (c). The FSPP is a simple and rapid process to fabricate particulate metal matrix composites (PMMCs), but the FSPP requires 3 or 4 passes along the same line to obtain homogeneous $\mathrm{PMMCs}^{8}$, and has difficulty in controlling the particle volume fraction (VF). The FSPP can also yield further refined grains and particles to enhance the mechanical properties ${ }^{8)}$, but it is disadvantageous for the thermal conductivity (TC) due to

* Corresponding author, E-mail: y-kimoto@omtri.or.jp the increase of interfacial thermal barriers ${ }^{9)}$. So in this study, we have applied a friction powder sintering (FPS) ${ }^{10-12)}$ shown in Fig. 1 (d) to produce high-VF PMMCs. FPS was developed by Hangai et al. to produce porous aluminum. They consolidated the powder mixture of $\mathrm{Al}$ and $\mathrm{NaCl}$ particles, and obtained open-cell porous $\mathrm{Al}$ after dissolving $\mathrm{NaCl}$ in the water. There are some reports of FPS using ceramic particles as a spacer material to form porous metal $^{10-13)}$. However, to our knowledge, there are few reports of FPS or a similar process ${ }^{14)}$ using ceramic particles as a filler material to form PMMCs.

In this study, we have produced Al-50 vol.\% SiC PMMCs via FPS and evaluated the TC of the composites. The TC has been (a) FSW

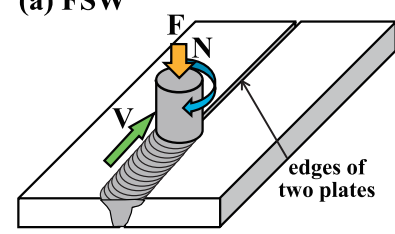

(c) FSPP

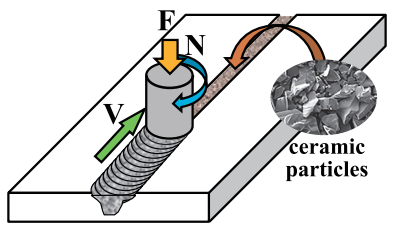

(b) FSP

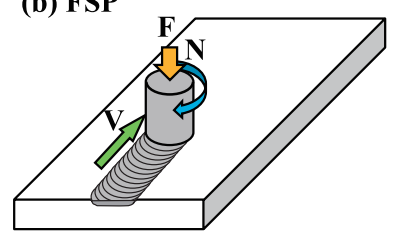

(d) FPS

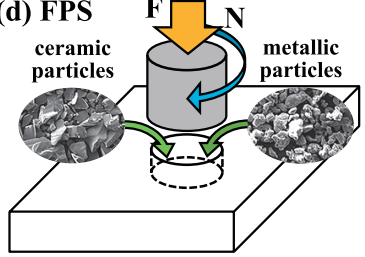

Fig. 1 Advances in friction stir technologies. 
compared to that via other processes ${ }^{15-21)}$ such as a spark plasma sintering (SPS) $)^{18-21)}$.

\section{Experimental Procedures}

\subsection{Starting Materials}

Scanning electron micrograph images of starting materials are shown in Fig. 2. The aluminum powder of Fig. 2 (a) is in -325 mesh (smaller than $44 \mu \mathrm{m}$ in diameter) with $99.5 \%$ purity (Mitsuwa Chemistry Co., Ltd.). SiC powders of $\alpha$-SiC (GMF-60FH2, Pasific Rundum Co., Ltd.) or $\beta$-SiC (GMF-CVD, Pasific Rundum Co., Ltd.) was used as a filler material. The $\alpha$-SiC particles are smaller than $300 \mu \mathrm{m}$ in diameter. The $\beta$-SiC powder was sieved to be composed of smaller particles than $300 \mu \mathrm{m}$ in diameter. The $\alpha$-SiC particles had broader size distribution compared to $\beta$-SiC ones.

\subsection{FPS Conditions}

An Al 1050 plate $(100 \mathrm{~mm} \times 100 \mathrm{~mm} \times 25 \mathrm{~mm})$ with a hole (16 $\mathrm{mm}$ in diameter and $5 \mathrm{~mm}$ in depth) was used as a die material in FPS. A columnar tool (20 mm in diameter) made of WC-Co cemented carbide was used as a punch material. The powder mixture of $\mathrm{Al}$ and $\mathrm{SiC}$ with both VFs $50 \%$ was filled into the hole, and the rotating tool (die) was inserted onto the hole coaxially. A tool rotating rate was $1500 \mathrm{rpm}$, and an applied load was $9.8 \mathrm{kN}$, corresponding to the pressure of $31 \mathrm{MPa}$. The sintering time after reaching the applied load was taken to be 1,2 or $2.5 \mathrm{~min}$.

\subsection{Characterizations}

The disc-shaped composite was formed after FPS. For density and TC measurements, a 10-mm square specimen with the thickness approximately $2 \mathrm{~mm}$ were taken from the center of the composite. The density of the square specimen was measured by Archimedes' principle. The relative density was defined as the measured density divided by the theoretical density of the composite without porosity. The theoretical density and the theoretical specific heat were calculated by the rule of mixture ${ }^{22}$. The thermal diffusivity of the composite was measured by the laser-flash method using NETZSCH LFA 457. The TC was calculated as the product of the measured thermal diffusivity, the theoretical density and theoretical specific heat ${ }^{22)}$. X-ray diffraction (XRD) measurement was performed on the center of the square specimen using Rigaku RINT2500V (Cu K $\alpha$ ). Macrostructure and microstructure were observed on the vertical cross section approximately $5 \mathrm{~mm}$ apart from the center of the discshaped composite using an optical microscopy (Nikon AZ100).

\section{Results and Discussions}

Table 1 summarizes the experimental conditions and results in the literatures and this work. The maximum TC obtained in this work has been $110 \mathrm{~W} / \mathrm{mK}$, which is significantly lower than the TC of the base metal $\left(\mathrm{Al}, 210 \mathrm{~W} / \mathrm{mK}^{23)}\right)$. The major factors influencing on the TC of the composite are the relative density, the TC of the filler, the particle size distribution and the interfacial reaction between $\mathrm{SiC}$ particles and the Al matrix. The FPS parameters in this study were the sintering time and the filler selection. Both parameters have affected the TC of the composites significantly.
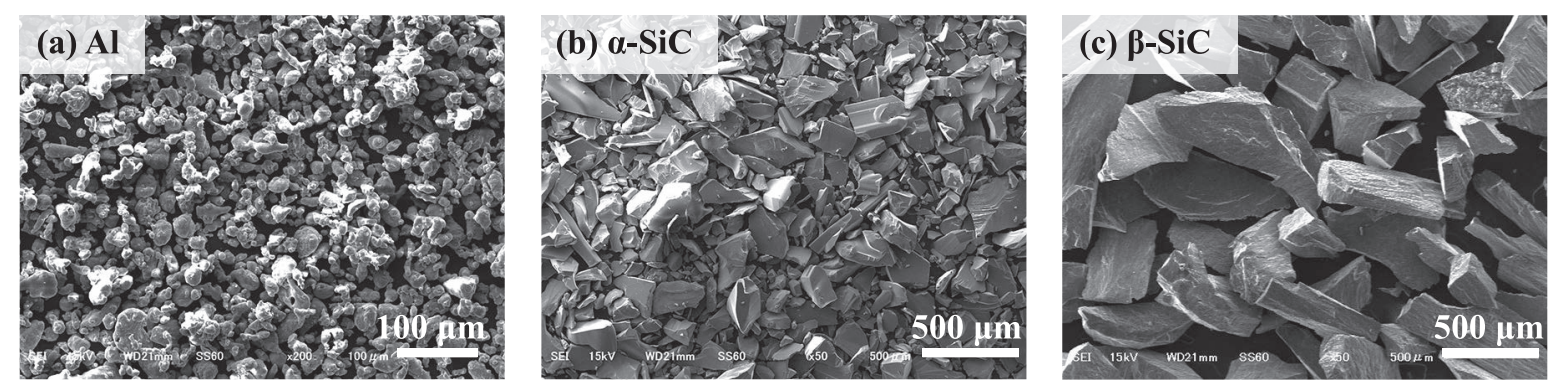

Fig. 2 Starting materials used in FPS.

Table 1 Overview on the $\mathrm{TC}$ of $\mathrm{Al} / \mathrm{SiC}$ PMMCs via various processes.

\begin{tabular}{|c|c|c|c|c|c|c|c|c|}
\hline Process & Filler & $\begin{array}{l}\text { VF } \\
(\%)\end{array}$ & $\begin{array}{c}\text { Particle } \\
\text { distribution }\end{array}$ & $\begin{array}{l}\text { Heating time } \\
\quad(\mathrm{sec})\end{array}$ & $\begin{array}{l}\text { Process time } \\
\quad(\mathrm{sec})\end{array}$ & $\begin{array}{l}\text { Relative density } \\
\qquad(\%)\end{array}$ & $\begin{array}{c}\mathrm{TC} \\
(\mathrm{W} / \mathrm{mK})\end{array}$ & $\begin{array}{l}\text { Author } \\
\text { (Ref.) }\end{array}$ \\
\hline Hot forging & $\alpha-\mathrm{SiC}$ & 66.3 & monomodal & 60 & 15 & 100 & 237 & C. Kawai ${ }^{15)}$ \\
\hline Hot forging & $\alpha-\mathrm{SiC}$ & 66.3 & monomodal & 60 & 15 & 94 & 100 & C. Kawai ${ }^{15)}$ \\
\hline Gas pressure infiltration & $\alpha-\mathrm{SiC}$ & 58 & bimodal & 6000 & 1800 & 99 & 228 & J. M. Molina ${ }^{16)}$ \\
\hline Pressureless infiltration & $\alpha-\mathrm{SiC}$ & 65 & bimodal & 560 & 7200 & 99 & 186 & K. $\mathrm{Chu}^{17)}$ \\
\hline SPS & $\alpha-\mathrm{SiC}$ & 55 & monomodal & 630 & 300 & 100 & 224 & K. $\mathrm{Chu}^{18)}$ \\
\hline SPS & $\alpha-\mathrm{SiC}$ & 50 & monomodal & 461 & 1560 & 100 & 252 & K. Mizuuchi ${ }^{19)}$ \\
\hline SPS & $\beta-\mathrm{SiC}$ & 45 & monomodal & 461 & 1560 & 100 & 216 & K. Mizuuchi ${ }^{20)}$ \\
\hline SPS & $\alpha-\mathrm{SiC}$ & 50 & bimodal & 461 & 1560 & 100 & 252 & K. Mizuuchi ${ }^{21)}$ \\
\hline FPS & $\alpha-\mathrm{SiC}$ & 50 & monomodal & \multicolumn{2}{|c|}{60} & 81 & 110 & This work \\
\hline FPS & $\alpha-\mathrm{SiC}$ & 50 & monomodal & \multicolumn{2}{|c|}{120} & 91 & 66 & This work \\
\hline FPS & $\beta-\mathrm{SiC}$ & 50 & monomodal & \multicolumn{2}{|c|}{120} & 89 & 38 & This work \\
\hline
\end{tabular}



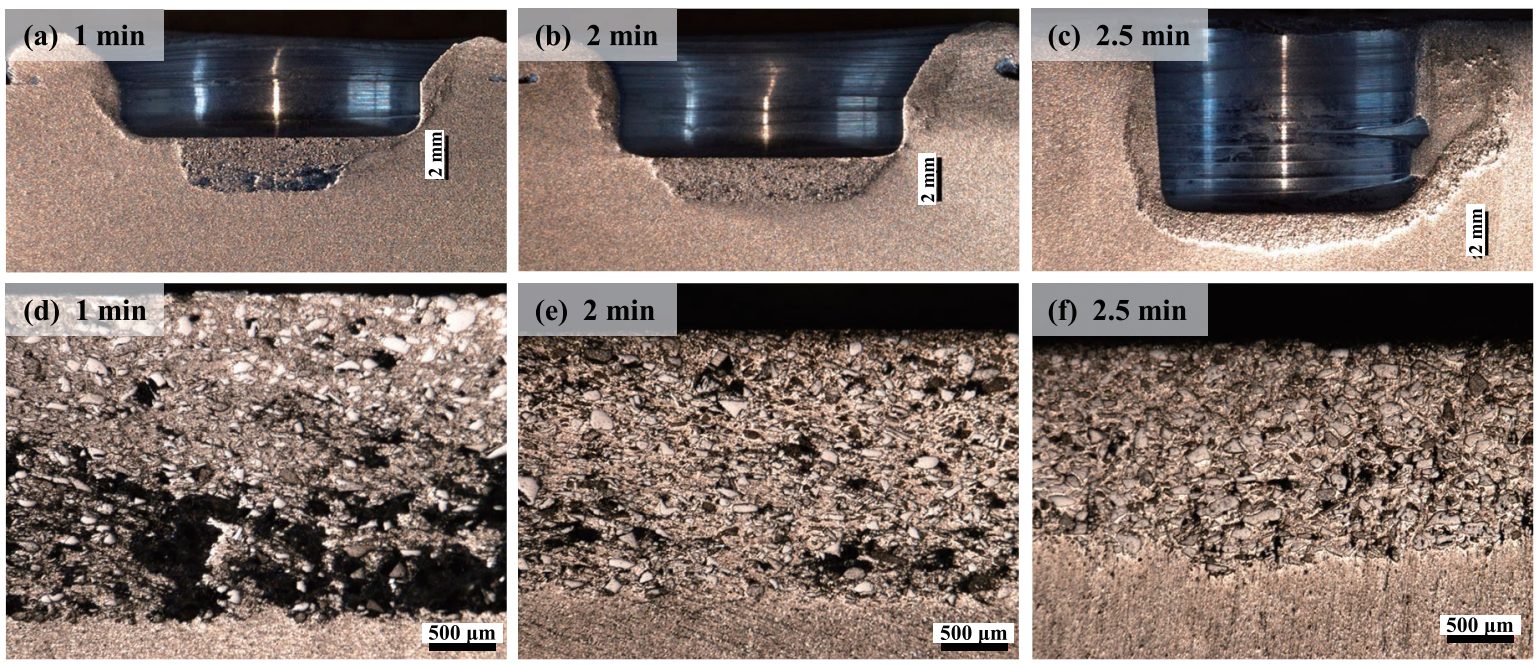

Fig. 3 Transitions of macrostructures and microstructures of the cross section of FPS samples.

\subsection{Dependence of the TC on the Sintering Time}

Fig. 3 shows the transitions of the macrostructure and microstructure of the cross section with the sintering time. A 1-min sintering has been able to densify only in the top side of the composite, and there are large pores in the bottom side of the composite. The relative density was $81 \%$, and the TC was $66 \mathrm{~W} / \mathrm{mK}$. A 2-min sintering has significantly reduced the pores and the relative density has reached $91 \%$. The TC has achieved $110 \mathrm{~W} / \mathrm{mK}$. This value is around a half of the bulk Al value $\left(210 \mathrm{~W} / \mathrm{mK}^{23)}\right)$, and slightly better than that of Al-66.3 vol.\% SiCp composite with a relative density $94 \%$ produced by a hot forging $\left(100 \mathrm{~W} / \mathrm{mK}^{15}\right)$. Further densification is necessary to derive the potential TC of the composite. A 2.5min sintering could make the composite denser, but the part of the composite has been rolled up by the side flow generated by the rotating tool. The sample for the density and TC measurement was difficult to be taken because of uneven thickness of the composite layer. To inhibit the side flow and to make the composite denser, using harder die material such as $\mathrm{Cu}$ may be recommended ${ }^{11)}$.

\subsection{Dependence of the TC on the Filler Selection}

The microstructural difference in the filler selection $(\alpha-\mathrm{SiC}$ or $\beta$-SiC) is shown in Fig. 4. In both cases, the fragmentation of $\mathrm{SiC}$ particles was not significant unlike the FSP for an $\mathrm{Al} / \mathrm{SiCp}$ composite $^{5)}$. In the case of $\alpha$-SiC, the TC of the composite $(66 \mathrm{~W} / \mathrm{mK})$ has been significantly higher than that of $\beta$-SiC composite $(38 \mathrm{~W} / \mathrm{mK})$, in spite of the lower density. One possible factor leading the better $\mathrm{TC}$ is the higher TC of the filler $\left(490 \mathrm{~W} / \mathrm{mK}^{24)}\right.$ and $360 \mathrm{~W} / \mathrm{mK}^{24)}$ for $\alpha-\mathrm{SiC}$ and $\beta-\mathrm{SiC}$, respectively). Another possible factor is that the particle size distribution of the $\alpha$-SiC composite was broader than that of the $\beta$-SiC composite as shown in Fig. 4. The broader distribution would be easier to fill the space between coarser particles with smaller ones, resulting in the elevated TC of the composite.

3.3 Interfacial Reaction between the Filler and Matrix during FPS

The interfacial reaction between $\mathrm{SiC}$ particles and $\mathrm{Al}$ matrix yields $\mathrm{Si}$ and $\mathrm{Al}_{4} \mathrm{C}_{3}$ with low TC and decreases the TC of the
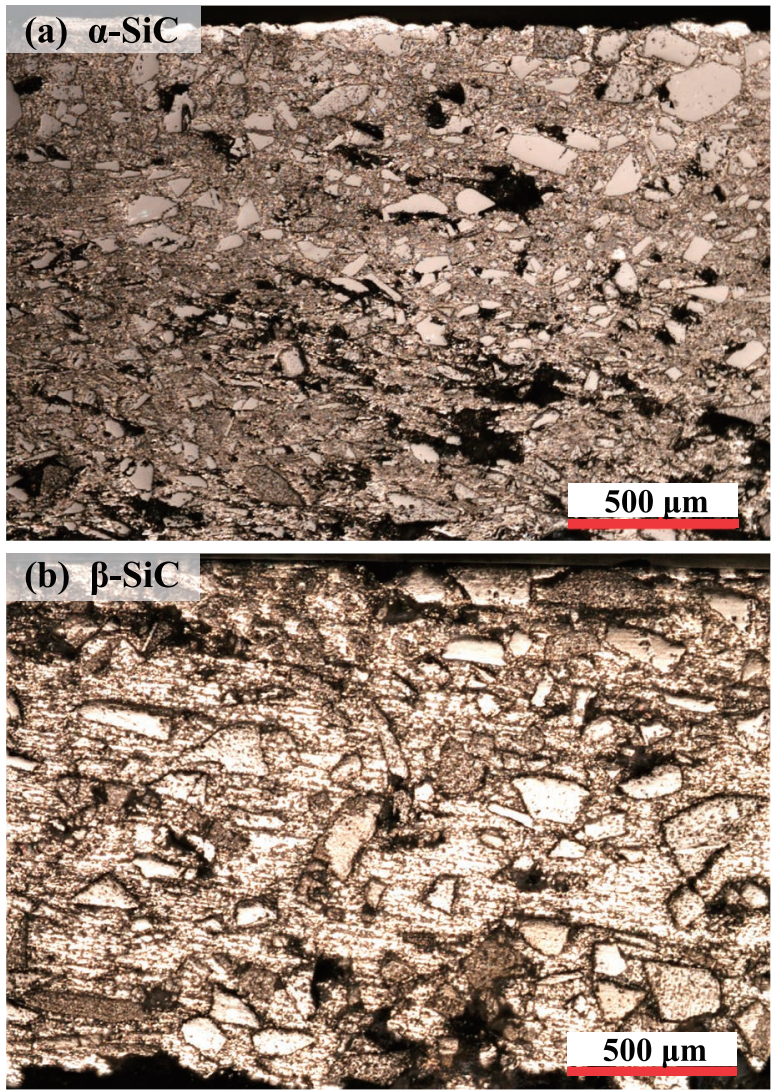

Fig. 4 Microstructures of the cross section of $\mathrm{Al} / \alpha-\mathrm{SiC}$ and $\mathrm{Al} / \beta-\mathrm{SiC}$ composites.

composite $^{15)}$. Fig. 5 shows a XRD diagram of the Al/ $\alpha-S i C$ composite produced via FPS under the 2-min sintering time. As in the $\mathrm{Al} / \alpha-\mathrm{SiC}$ composite fabrication via a hot forging ${ }^{15)}$, the distinct Si peaks and very slight peaks have been detected. It may be suspected of contributing to the reduction of TC of the composite as well as the low relative density. In our previous study ${ }^{25)}$, we have produced Al-33 vol.\% SiCp surface composite via 3-time accumulative FSPP under the same rotational rate of $1500 \mathrm{rpm}$, but the formations of $\mathrm{Si}$ and $\mathrm{Al}_{4} \mathrm{C}_{3}$ were negligible from the XRD 


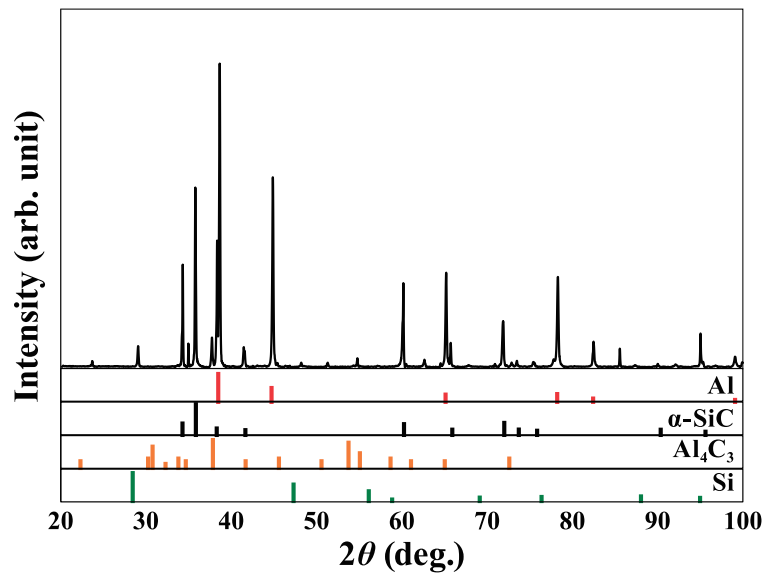

Fig. 5 XRD diagram of the composite produced via 2-min FPS.

measurement. It is probably because the traverse of the rotating tool suppressed the local elevation of temperature.

3.4 Comparison with Other Processes

The advantages and disadvantages of FPS and other processes are compared in the Table 1. At the present, the $\mathrm{Al} / \mathrm{SiCp}$ composites via FPS have considerably lower relative density and TC. However, the process time of FPS is one-order of magnitude shorter compared to the gas pressure infiltration, pressureless infiltration and SPS. The tool rotation might promote the rearrangement of particles and accelerate sintering. FPS can simultaneously perform heating and sintering of powders by the frictional heat and downward pressure. FPS is characterized as a special sintering process that requires no heating time and equipment. FPS can be a candidate of a rapid sintering technology using low-cost equipment. Further densification of the composite is the main subject toward realizing high-TC PMMCs.

\section{Summary}

FPS has been applied to fabricate Al-50 vol.\% SiC PMMCs. The FPS under the rotating rate of $1500 \mathrm{rpm}$, applied load of $9.8 \mathrm{kN}$, and sintering time of $2 \mathrm{~min}$ has produced a PMMC with the relative density $91 \%$ and the TC $110 \mathrm{~W} / \mathrm{mK}$. The low TC can be attributed to the low relative density of the composite and the interfacial reaction between $\mathrm{SiC}$ particles and $\mathrm{Al}$ matrix. FPS is potential to be a practical sintering technology if the densification of the composite becomes possible in the future.

\section{Acknowledgements}

This study was supported by Japan Science and Technology Agency (JST) under Collaborative Research Based on Industrial Demand "Heterogeneous Structure Control: Towards Innovative Development of Metallic Structural Materials".

\section{References}

1) W. M. Thomas, et al.: "Friction Stir Butt Welding", International patent application No. PCT/GB92/02203 and GB patent application No. 9125978.8 (1991).

2) R. S. Mishra, Z. Y. Ma: "Friction stir welding and processing", Mater. Sci. Eng. R, 50 (2005) 1-78.

3) R. S. Mishra, et al.: "High strain rate superplasticity in a friction stir processed 7075 Al alloy”, Scr. Mater., 42 (2000) 163-168

4) Z. Y. Ma, et al.: "Effect of multiple-pass friction stir processing on microstructure and tensile properties of a cast aluminumsilicon alloy”, Scr. Mater., 54 (2006) 1623-1626.

5) H. Izadi, et al.: "Friction Stir Processing of $\mathrm{Al} / \mathrm{SiC}$ Composites Fabricated by Powder Metallurgy", J. Mater. Process. Technol., 213 (2013) 1900-1907.

6) R. S. Mishra, Z. Y. Ma: "Friction stir processing: a novel technique for fabrication of surface composite", Mater. Sci. Eng. A, 341 (2003) 307-310.

7) Y. Morisada, et al.: "MWCNTs/AZ31 surface composites fabricated by friction stir processing”, Mater. Sci. Eng. A, 419 (2006) 344-348.

8) Y. Kimoto, et al.: "Compositing Technology through Friction Stir Processing”, J. Smart Process., 4 (2015) 148-152.

9) D. P. H. Hasselman, et al.: "Effect of Reinforcement Particle Size on the Thermal Conductivity of a Particulate-Silicon Carbide-Reinforced Aluminum Matrix Composite", J. Am. Ceram. Soc., 75 (1992) 3137-3140.

10) Y. Hangai, et al.: "Friction Powder Compaction for Fabrication of Open-Cell Aluminum Foam by the Sintering and Dissolution Process Route", Metall. Mater. Trans. A, 43 (2012) 802-805.

11) Y. Hangai, et al.: "Effect of Die Material on Compressive Properties of Open-Cell Porous Aluminum Fabricated by Friction Powder Compaction Process”, Mater. Trans., 54 (2013) 1057-1059.

12) Y. Hangai, et al.: "Fabrication of Open-Cell Porous Aluminum by Friction Powder Sintering Process", J. Jpn. Inst. Light Met., 64 (2014) 628-632.

13) Y. Hangai, et al.: "Friction Powder Compaction Process for Fabricating Open-Celled Cu Form by Sintering-Dissolution Process Route Using $\mathrm{NaCl}$ Space Holder”, Mater. Sci. Eng. A, 585 (2013) 468-474

14) E. Maeda, et al.: "Consolidating and Particle Dispersing Process in Compressive Torsion Forming of SiC/Aluminum Powder Mixture", J. Jpn. Soc. Technol. Plast., 40 (1999) $35-$ 39.

15) C. Kawai: "Fabrication of Al-SiC Composites Using a HotForging Technique and Their Thermal Conductivity", J. Ceram. Soc. Jpn., 110 (2002) 1016-1020.

16) J. M. Molina, et al.: "Thermal Conductivity of Al-SiC Composites with Monomodal and Bimodal Particle Size Distribution”, Mater. Sci. Eng. A, 480 (2008) 483-488.

17) K. Chu, et al.: "The Thermal Conductivity of Pressure Infiltrated $\mathrm{SiCp} / \mathrm{Al}$ Composites with Various Size Distributions: 
Experimental Study and Modeling", Mater. Des., 30 (2009) 3497-3503.

18) K. Chu, et al.: "Thermal Conductivity of Spark Plasma Sintering Consolidated $\mathrm{SiCp} / \mathrm{Al}$ Composites Containing Pores: Numerical Study and Experimental Validation", Compos. Part A Appl. Sci. Manuf., 41 (2010) 161-167.

19) K. Mizuuchi, et al.: "Thermal Properties of $\mathrm{Al} / \mathrm{SiC}$ Composites Fabricated in Continuous Solid-Liquid Co-Existent State by SPS”, J. Jpn. Soc. Powder Powder Metallurgy, 58 (2011) 160164.

20) K. Mizuuchi, et al.: "Thermal Properties of $\mathrm{Al} / \beta-\mathrm{SiC}$ Composite Fabricated in Continuous Solid-Liquid Co-Existent State by SPS”, J. Jpn. Soc. Powder Powder Metallurgy, 59 (2012) 557-563.

21) K. Mizuuchi, et al.: "Effect of Bimodal Distribution of $\mathrm{SiC}$
Particle Size on Thermal Properties of $\mathrm{Al} / \mathrm{SiC}$ Composite Fabricated by SPS", J. Jpn. Soc. Powder Powder Metallurgy, 60 (2013) 202-208.

22) K. Yoshida, H. Morigami: "Thermal Properties of Diamond/ Copper Composite Material”, Microelectron. Reliab., 44 (2004) 303-308

23) ASM Engineered Mater. Reference Book, 2nd Edition, M. Bauccio, Ed. ASM Inter., Mater. Park, OH, (1994) 360-369.

24) Y. Goldberg et al.: Properties of Advanced Semiconductor Materials GaN, AlN, SiC, BN, SiC, SiGe. Eds. Levinshtein M.E., et al., John Wiley \& Sons, Inc., New York, (2001) 93148

25) Y. Kimoto, et al.: “Al/SiCp Metal Matrix Composites Fabricated via Friction Stir Powder Processing", J. Jpn. Soc. Powder Powder Metallurgy, 62 (2015) 258-262. 